Europe's Journal of Psychology 4/2009, pp. 20-39

www.ejop.org

\title{
Emotional Intelligence and Psychological Distress: Testing the Mediatory Role of Affectivity
}

Jahanvash KARIM

CERGAM

IAE d'Aix-en-Provence,

France

\begin{abstract}
The study tested the extent to which positive and negative affect at work mediate emotional intelligence effects on psychological distress. Participants were 200 middlelevel managers who completed the Wong and Law Emotional Intelligence Scale, 20item affectivity scale, and a measure of psychological distress. Results using covariance based structural equation modeling indicated that only negative affect fully mediated the relationship between emotional intelligence and psychological distress. Furthermore, the direct effect of emotional intelligence was stronger for positive affect as compared to its influence on negative affect. Finally, negative affect had a significant direct influence on psychological distress, whereas the relationship between positive affect and psychological distress was insignificant.
\end{abstract}

Keywords - Emotional intelligence; affectivity; distress; mediation.

One area of emotion research that has received considerable scholarly attention in recent years is "Emotional Intelligence (EI)" (Goleman, 1995; Salovey \& Mayer, 1990). The popularity of El concept during the last decade has lead organizational behavior researchers to examine its applicability within work settings. For example, empirical studies have demonstrated that El is related to stress (Miklolajczak, Menil, \& Luminet, 2007), performance (Slaski \& Cartwright, 2003), conflict and innovation (Suliman \& Al-Shaikh, 2006), job satisfaction and organizational commitment (Carmeli, 2003; Kafetsios, 2007). There is accumulating evidence that El influences psychological distress within work setting (Besharat, 2007; Dulewicz, Higgs, \& Slaski, 
2003; Tsaousis \& Nikolaou, 2005). While the role of El in predicting psychological distress is well established, the mechanism through which El predicts psychological distress is little researched. To my knowledge, there is no study testing the extent to which affective experiences may mediate the relationship between $\mathrm{El}$ and psychological distress. Affective Events Theory (AET: Weiss \& Cropanzano, 1996) proposes that antecedent events at work (with dispositions) lead to affective states that in turn, lead to attitudinal and behavioral outcomes.

This study sought to test a model of El that includes positive affectivity (PA) and negative affectivity (NA) in the El-psychological distress relationship. Psychological distress is a serious problem faced by many employees within work setting. An understanding of the relationship between El, affectivity, and psychological distress will help managers to take care of problem of distress in workers. Furthermore, most of the previous studies relating El to psychological distress have been conducted in the West raising the questions about the extent to which these findings are generalizable to the East. This study adds to the literature by testing the proposed model in the South Asian context, thus providing some empirical cross-cultural validity of El-psychological distress relationship.

\section{Conceptual Background and Hypothesis}

Emotional Intelligence

Salovey and Mayer (1990) were first to utilize the term "emotional intelligence". They drew on relevant evidence from previous intelligence and emotion research and presented the first model of El. Their model included three distinct components: appraisal and expression of emotion, regulation of emotions, and utilization of emotional information in thinking and acting. Later, Mayer and Salovey refined their 1990's model, and defined El as, " the ability to perceive accurately, appraise, and express emotions; the ability to access and/or generate feelings when they facilitate thought; the ability to understand emotion and emotional knowledge; and the ability to regulate emotions to promote emotional and intellectual growth" (Mayer \& Salovey, 1997, P.10).

Since Salovey and Mayer's (1990) conceptualization, a considerable amount of theoretical and empirical research has been done on the conceptualization of El (e.g. Bar-On, 1997; Goleman, 1995; Mayer \& Salovey, 1997; Petrides \& Furnham, 2001), as well as, its measures (e.g., Emotional Quotient Inventory: Bar-On, 1997; Mayer-Salovey-Caruso Emotional Intelligence Test: Mayer et al., 2003; Self-report 
Emotional Intelligence Test: Schutte et al., 1998; Trait Emotional Intelligence Questionnaire: Petrides, Pérez-Gonzalez, \& Furnham, 2007). The plethora and diversity of El models and measures in the field give rise to the need for a way to classify them. Currently there are mainly two approaches to conceptualizing and measuring El: 'Ability El' and 'Trait El' (Petrides \& Furnham, 2001). Ability models have been identified as those that define El as 'intelligence' in the traditional sense (e.g., Mayer \& Salovey, 1997; Salovey \& Mayer, 1990). Proponents of ability El conceive El as an ability to process the information contained in emotions to determine the meaning of emotions and their connections to one another; and to use emotional information as the basis for thought and decision making (e.g., Salovey \& Mayer, 1990). Ability El is measured through performance tests with correct and incorrect answers, for example, Mayer-Salovey-Caruso emotional Intelligence Test (MSCEIT) (Mayer et al., 2003). On the other hand, trait El is defined as "constellation of behavioral dispositions and self perceptions concerning one's ability to recognize, process, and utilize emotion laden information" (Petrides \& Furnham, 2001, p. 426). Basically, the trait El construct encompasses two kinds of variance: variance covered by personality dimensions (Big Five \& Giant Three) and variance that lies outside these dimensions (Petrides, Pita, \& Kokkinaki, 2007). In contrast to ability El, the trait El is measured via self-reports. In short, the distinction between ability El (cognitiveemotional ability) and trait El (trait emotional self-efficacy) is mainly based on the method of measurement (self-report versus performance based) and should not be confused with Mayer, Salovey, and Caruso's (2000) distinction between 'ability El models' and 'Mixed El models'. In contrast to Petrides, and Furnham's (2001) distinction, Mayer, Salovey, \& Caruso (2000) conceive mixed models of El (e.g., BarOn, 1997; Goleman, 1995) as those which "mixes" cognitive abilities with other characteristics. In line with Petrides and Furnham's (2001) approach (trait El vs. ability El), the present paper seeks to find the relationships between trait El, psychological distress, and affectivity.

El and Affectivity

Affectivity is a general tendency to experience a particular mood or to react to objects in a particular way (Lazarus, 1993). Affectivity is split up into two distinct dimensions: Positive affect (PA) and negative affect (NA). PA refers to tendency of experiencing good feelings such as enthusiastic, active, and alert, whereas, NA refers to having bad feelings such as anxiety and disgust (Watson, Clark, \& Tellegen, 1988). Research has documented that PA and NA are two independent separate constructs (Morris \& Feldman, 1996; Watson \& Clark, 1984; Watson, Clark, \& Tellegen, 1988). 
According to Lopes et al. (2006), people are usually motivated to seek pleasant feelings and avoid unpleasant ones. The El abilities can help people to identify and interpret cues that inform self-regulatory action to nurture positive affect and avoid negative affect (Lopes et al., 2006; Mayer \& Salovey, 1997). Various researches have documented a positive relationship between El and PA and negative relationship between El and NA (e.g., Kafetsios \& Zampetakis, 2008; Lopes et al., 2006; Sevdalis, Petrides, \& Harvey, 2007). Thus, it is expected that trait El will be positively associated with PA and inversely to NA at work.

Hypothesis 1a: There is a positive relationship between El and PA.

Hypothesis $1 \mathrm{~b}$ : There is a negative relationship between El and NA.

Psychological Distress

Most of theorists look at a broader definition of psychological health containing two factors: Psychological well-being (positive mental health states like life satisfaction) and psychological distress (negative mental health states like anxiety and depression) (Massée et al.,1998; Veit \& Ware, 1983; Wilkinson \& Walford, 1998). Although psychological distress has been a topic of interest to psychologists and social scientists (Bruch, Rivet, \& Laurenti, 2000; Massée, 2000), the study of this construct has garnered attention within the work setting during the past few years (e.g., Besharat, 2007; Dulewicz, Higgs, \& Slaski, 2003; Tsaousis \& Nikolaou, 2005).

The theoretical structure of the construct of psychological distress and its operationalization has been subjected to extensive research (e.g., Goldberg, 1978; Massée et al., 1998; Ridner, 2004). Ridner (2004) after extensive review of literature pointed out that, psychological distress is often embedded in the context of stress, strain, and distress and is seldom treated as a distinct concept. She differentiated between strain, stress, distress, and psychological distress and defined the construct of psychological distress as, "the unique discomforting, emotional state experienced by an individual to response to a specific stressor or demand that results in harm, either temporary or permanent, to the person." (p. 539). Psychological distress is a complex and multidimensional construct (Massée et al., 1998; Ridner, 2004; Veit \& Ware, 1983, Wilkinson \& Walford, 1998). In its simplest form psychological distress is viewed as a construct that represents aspects of negative functioning. For instance, according to Massée et al., (1998), psychological distress is usually operationalized by measures of self-depreciation, irritability, anxiety, depression, and social disengagement. 
Affectivity and Psychological Distress

It has been argued that affectivity may affect perceived level of psychological health by influencing perceptions of self or environment (Oliver \& Brough, 2002). Individuals with high levels of NA are more likely to appraise events as threatening (Gallagher, 1990), tend to view their environment more negatively (Spector et al., 2000), report more negative interpretations of trivial problems (Watson \& Pennebaker, 1989), and encode more negative information (Larsen, 1992). This highly negative view of their objective environment lead them to rate stressors as highly aversive experiences, which in turn leads to poorer psychological well-being outcomes (e.g., anxiety \& depression) (Oliver \& Brough, 2002; Spector et al., 2000). Thus, it is expected that PA will be negatively associated with psychological distress and NA will be positively associated with psychological distress.

Hypothesis 2a: There is a negative relationship between PA and psychological distress.

Hypothesis 2b: There is a positive relationship between NA and psychological distress.

El and Psychological Distress

In their review of psychological well-being research, Diener and colleagues (Diener et al., 1999) assert that, "personality is one of the strongest and most consistent predictors of subjective well-being" (p. 279). In this nexus, there are several reasons why trait El may influence psychological distress. Research suggests that El abilities and traits contribute to good physical and psychological health (Salovey et al., 1999; Salovey et al., 2000; Tsaousis, \& Nikolaou, 2005). Emotionally intelligent individuals have good physical and psychological health because they are better able to cope with life's challenges and can control their emotions more effectively (Taylor, 2001). In literature, various empirical studies have well documented the significant negative relationship between trait El and psychological distress (e.g., Besharat, 2007; Dulewicz, Higgs, \& Slaski, 2003; Tsaousis \& Nikolaou, 2005) and between trait El and sub dimensions of psychological distress, such as, depression and anxiety (Bauld \& Brown, 2009; Extremera \& Fernàndez-Berrocal, 2006; Fernandez-Berrocal et al., 2006).

Recently, researchers have argued that affective states at work, might serve to be the linking mechanism through which El affects a variety of employee behavior and organizational outcomes (e.g., Kafetsios, 2007; Kafetsios and Zampetakis, 2008). The study of affective states at work is an important area of organizational behavior research (Ashkanasy, Hartel, and Zerbe, 2000) and help in understanding the 
processes underlying the effects of various working conditions, work events and personality dispositions on various work attitudes, behaviors and individual's psychological states (Kafetsios, 2007; Kafetsios \& Zampetakis, 2008; Weiss \& Cropanzano, 1996). Affective Events Theory (AET) (Weiss \& Cropanzano, 1996) proposes that antecedent events at work with dispositions lead to affective states that in turn, lead to attitudinal and behavioral outcomes. Relevant to current study, AET suggests that dispositions (personality) may directly influence the employees' affective reactions. Thus, it is important to understand specific information about different dispositions in addition to work events in order to make predictions about individual's behavior. Individual differences influence reactions to the same work event, and these differences in reactions lead to different types of behaviors and attitudes (Weiss \& Cropanzano, 1996). Various studies have supported the idea that affective states mediate the effect of work events and/or dispositions on outcomes (e.g., Fisher, 2000; Kafetsios, 2007; Kafetsios \& Zampetakis, 2008; Weiss, Nicholas, \& Daus, 1999). Thus,

Hypothesis 3: PA and NA mediate El effects on psychological distress.

Method

Participants

The sample for this study consisted of 206 middle level managers from three public sector organizations situated in Pakistan. 95 participants of the total sample (46 percent) were males and 111 (54 percent) were females. The mean age for this sample was 31.48 years ( $S D=8.10)$. The sample was collected using non-probability purposive sampling method in order to obtain the appropriate number of participants for the study. Purposive sampling involves collecting any cases that contain the most representative attributes of the population (Cohen, Manion, \& Morrison, 2000, p.99). Before distribution of questionnaires, permission was obtained from each of the organization. Attached to the survey instrument was a letter that explained the objective of the survey in general terms, assured respondents of the confidentiality of their responses, and notified them that participating in the survey was voluntary. All participants were treated in accordance with the "Ethical principles of Psychologists Code of Conduct" (American Psychological Association, 2002). Administration of the questionnaires was carried out by post graduate students who acted as research assistants and no monetary incentive was provided. 
Instruments

Wong and Law Emotional Intelligence Scale (WLEIS: Wong \& Law. 2002). WLEIS consists of 16 items and taps individuals' knowledge about their own emotional abilities rather than their actual capacities. Specifically, the WLEIS is a measure of beliefs concerning self-emotional appraisal (SEA) (e.g., "I have a good sense of why I have certain feelings most of the time"), others' emotional appraisal (OEA)(e.g., "I always know my friends' emotions from their behavior"), regulation of emotion (ROE) (e.g., "I always set goals for myself and then try my best to achieve them"), and use of emotion (UOE) (e.g., "I am able to control my temper and handle difficulties rationally"). The response scale has been seven point Likert-type scale ranging from one (strongly disagree) to seven (strongly agree). Coefficients alphas for the four dimensions were: SEA: .80; OEA: .82; ROE: .81; UOE: .82.

Affectivity. Affectivity was measured by 20 items Positive and Negative Affect Schedule (PANAS) (Watson, Clark, \& Tellegen, 1988). PANAS is composed of two tenitem mood scales one to measure positive affectivity and the other to measure negativity affectivity. The higher scores on both PA and NA items indicate the tendency to experience a positive and negative mood. The ten positive affective states were: motivated, excited, feel strong, enthusiastic, proud, alert, inspired, determined, attentive, and active. The ten negative affective states were: distressed, upset, guilty, scared, hostile, irritable, ashamed, nervous, jittery, and afraid. Research has demonstrated the sound reliability of PANAS (i.e., Morris \& Feldman, 1996). Respondents were requested to rate the statement on a 5-point scale (not at all to extremely) by comparing themselves during the past 2 weeks with their 'usual selves'. In this study, the positive and negative affect parts of PANAS had good internal consistency (Alphas .71 and .85 respectively).

Psychological distress. Psychological distress was measured by Chan's (2005) twenty item scale. This scale measures psychological distress in terms of current nonpsychotic symptoms in the five symptom areas represented by scales of health concerns, sleep problems, anxiety, dysphoria, and suicidal ideas. Respondents were requested to rate each symptom statement on a 5-point scale (not at all to extremely) by comparing themselves during the past 2 weeks with their 'usual selves'. Coefficients alphas for the five dimensions were: health concerns: .75; sleep problems: .68; anxiety: .60; dysphoria: .86; and suicidal ideas: .78. 
Statistical Analysis

Prior to hypothesis testing data were tested for missing values and deviation from normality. Model fitting was performed with the help of AMOS (Arbuckle, 2006). Covariance based structural model (CBSEM) was analyzed and interpreted in two stages: the measurement model and the structural model. The measurement model relates to the relations between manifest variables (observed items) and latent variables. The measurement model is tested by assessing the discriminability of the constructs in the model. This ensures that only valid constructs' measures are used before assessing the nature of relationships in the overall model. For testing the measurement model (discriminant validity of four constructs), chi-square difference test was employed (Anderson \& Gerbing, 1988; Bagozzi \& Phillips, 1982). The chisquare values for unconstrained model and the chi-square value for fully constrained model (all correlations constrained to 1) were determined. According to Anderson and Gerbing (1988, p.416) and Bagozzi and Phillips (1982, p.476), if the $X^{2}$ for the first model is significantly smaller than second model, discriminant validity is achieved. This is because the better fitting model is the one where the two dimensions/constructs are viewed as distinctly different or not perfectly correlated.

Structural model specifies relations between latent constructs. The structural model is tested by estimating the paths between the constructs. Structural model was tested by computing path coefficients (Bs). A bootstrapping procedure using 1000 subsamples was performed to evaluate the statistical significance of each path coefficient. AMOS (Arbuckle, 2006) performs parametric bootstraps to find an approximate confidence interval for any model parameter under normal distribution theory. Steiger's Power Anlaysis (StatSoft, 2001) was used to estimate SEM modellevel power. Various fit indices were used to assess the fit of the model to the data, i.e., X2/df, CFI, GFI, AGFI, RMSEA, and AIC. According to Hair et al. (2006), multiple indices should be used to assess a model's goodness of fit. The fit indices should include: the Chi-square value and associated degree of freedom; one absolute fit index (like the GFI, RMSEA, or SRMR); one incremental fit index (like CFI or TLI); one goodness of fit index (like GFI, CFI, or TLI); and one badness of fit index (like RMSEA, SRMR). A $X^{2} / d f$ value close to 2 indicates an acceptable fit (Bentler \& Bonett, 1980) and the value close to 0.90 for CFI and GFI indicates a good fit (Schumacker \& Lomax, 1996). The value below 0.08 for root mean square error of approximation (RMSEA), a measure that takes into account the error of approximation in the population, indicates good fit (Browne \& Cudeck, 1993). Regarding AIC, the model with smallest AIC value is considered to be the best model (Schumacker \& Lomax, 1996). 
Results

Missing Value Analysis, Data Cleaning, and Item Parceling

Prior to hypothesis testing, the validity of participants' responses was examined. In order to make data entry errors unlikely, the data was entered twice and comparison was made between two entries for data entry mistakes (Barchard \& Christensen, 2007). Little's (1988) missing completely at random (MCAR) test revealed that the missing data were missing completely at random $\left(X^{2}=810.72 . d f=\right.$ 935, $p>$.05). When the missing data is MCAR, any imputation method can be used (Hair et al., 2006). Expectation-maximization (EM) method was employed to impute missing values.

Values of skewness and kurtosis below the absolute value of 1 can be considered as acceptable (Miles and Shevlin, 2004). With the exception of 5 items, all items showed skewness and kurtosis smaller than 1 and these exceptions were close to the criterion. As well as, a visual check of $Q Q$-plots and histograms also revealed unimodel distribution for all items. Three cases with extremely low z scores were found to be univariate outliers and three cases were identified through Mahalanobis' distance as multivariate outliers with $p<.001$. These six cases were removed from subsequent analysis.

Table 1 presents means, standard deviations and intercorrelations among variables. El was significantly related to psychological distress $(r=-.15, p<.05)$, positive affect ( $r$ $=.41, p<.001)$ and negative affect $(r=-.28, p<.001)$. Furthermore, psychological distress was significantly related to negative affect $(r=.53, p<.001)$.

Table 1

Descriptive statistics and inter-scale correlations

\begin{tabular}{|c|c|c|c|c|c|c|c|c|}
\hline & $M$ & $S D$ & 1 & 2 & 3 & 4 & 5 & 6 \\
\hline \multicolumn{9}{|l|}{ 1. Gendera } \\
\hline 2. Age & 31.48 & 8.10 & $0.23^{* *}$ & & & & & \\
\hline 3. El & 5.63 & .89 & -.14 & -.06 & (.89) & & & \\
\hline 4. Psychological distress & 1.97 & .68 & $-.16^{*}$ & -.07 & $-.15^{*}$ & (.88) & & \\
\hline 5. Positive affect & 3.69 & .56 & $-.17^{*}$ & -.11 & $.41^{* *}$ & -.11 & $(.71)$ & \\
\hline 6. Negative affect & 1.83 & .74 & -.09 & -.06 & $-.28^{* *}$ & $.53^{* *}$ & $-.18^{*}$ & $(.85)$ \\
\hline $\begin{array}{l}\text { Note }: N=200 . \text { Internal re } \\
\text { a Gender is coded } 0=\text { fer } \\
{ }^{*} \mathrm{P}<0.05 \\
{ }^{* *} \mathrm{P}<0.01\end{array}$ & $\begin{array}{l}\text { abilities } \\
\text { ale } 1=\end{array}$ & $\begin{array}{l}\text { parer } \\
\text { ale. }\end{array}$ & sis. & & & & & \\
\hline
\end{tabular}


The practice of item parceling (combining items into small groups of items within scales or subscales) is much popular for reducing data analysis problems e.g., nonnormality and small sample sizes (e.g., Bandalos, 2002). Thus, in order to allow robust statistics, the size of the model was reduced by creating item parcels for 20 items PANAS (Watson, Clark, \& Tellegen, 1988). Based on factor loadings (exploratory factor analysis) for each PANAS i.e., ten item's PA scale and ten item's NA scale, two 5-item parcels were created. Coefficient alphas for two PA scales were: PA 1: .64; and PA2: .71. And coefficient alphas for two NA scales were: NA1: .70; and NA2: .80.

\section{Measurement Model}

Table 2 presents the fit statistics for measurement model. Results indicate that, the hypothesized measurement model fit the data well than a single factor model, both in terms of various fit indices and chi-square difference test.

Table 2

Fit statistics for measurement models

\begin{tabular}{ccccccccc}
\hline & $X^{2}$ & df & $X^{2} / d f$ & $\Delta X^{2}$ & GFI & CFI & RMSEA & AIC \\
\hline Four-factor & $171.62^{* *}$ & 60 & 2.90 & & .92 & .91 & $.081(90 \% \mathrm{Cl}: .07-.10)$ & 235.62 \\
one factor & $456.16^{* *}$ & 65 & 7.01 & $284.54^{* *}$ & .69 & .55 & $.17(90 \% \mathrm{Cl}: .15-.18)$ & 508.16 \\
\hline${ }^{* *} p<0.001$. & & & & & & & &
\end{tabular}

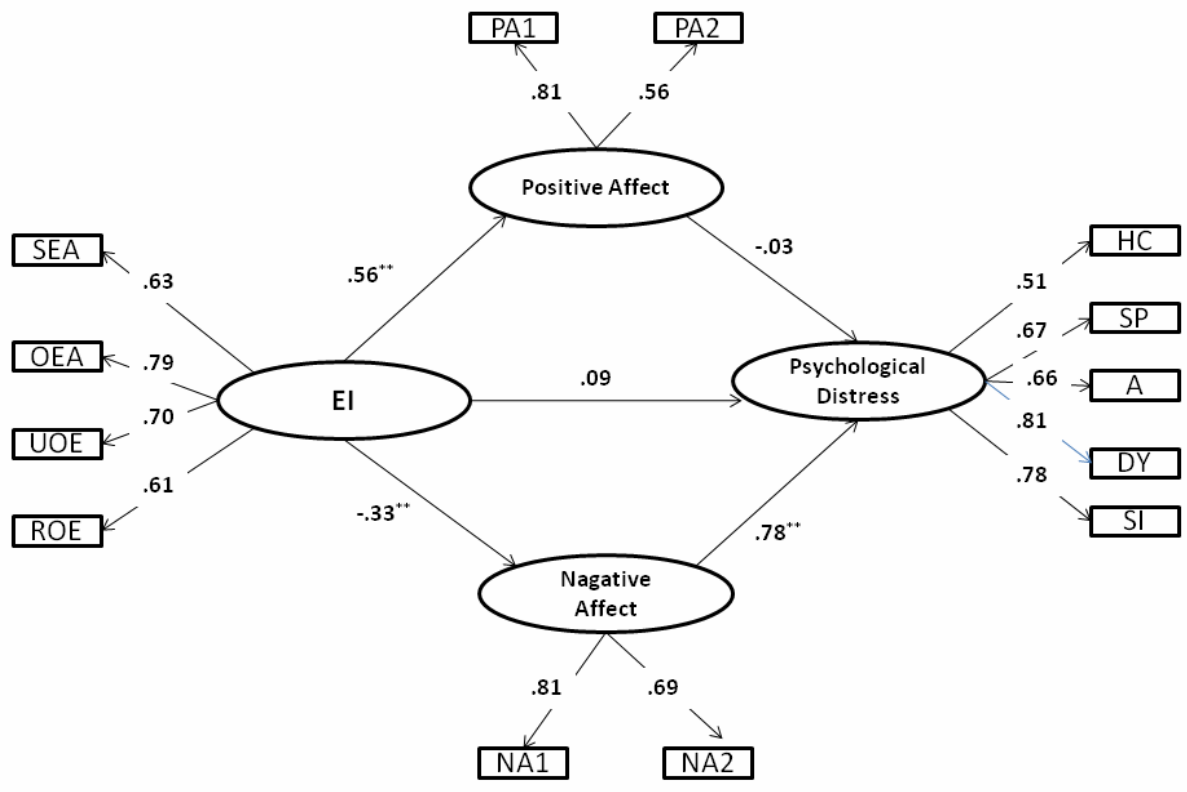

Figure 1. Structural model. SEA = self emotion appraisal; OEA = Others emotion appraisal; $\mathrm{UOE}=$ use of emotion; $\mathrm{ROE}$ = regulation of emotion; $\mathrm{PA}=$ positive affect; $\mathrm{NA}=$ negative affect; $\mathrm{HC}=$ health concerns; $\mathrm{SP}=$ sleep problems; $\mathrm{A}=$ anxiety; $\mathrm{DY}=$ dysophoria; $\mathrm{SI}=$ suicidal ideas. ${ }^{* *} \mathrm{P}<.01$. 
Structural Model

The structural model revealed a good fit to the data: $X^{2}(60, N=200)=172.65, p<$ $0.001 ; \mathrm{GFI}=.92 ; \mathrm{CFI}=.91$ and RMSEA $=.081$ (90\% $\mathrm{Cl}=.07-0.10)$. Steiger's Power Analysis (StatSoft, 2001) suggested a power of .83 for the model $(\varepsilon 1=.08, a=.05, N=$ $200, d f=60$ ). The results indicated that the effect of El on psychological distress was partially mediated by PA and NA. The standardized direct effect of $\mathrm{El}$ on psychological distress was .08 (95\% percentile confidence interval:(-.08) - (.30), $p$ > .34). El had significant direct effects on NA (-.34, 95\% percentile confidence interval:(-.52)-(-.15), $\mathrm{p}=.003)$ and PA (.56, 95\% percentile confidence interval: (.42)(.73), $p<0.05)$. Indirect effect of El on psychological distress was $(-.28,95 \%$ percentile confidence interval: (-.52)-(-.09), $p<.01)$. In sum, the standardized total effect of El on psychological distress was -.19 (95\% percentile confidence interval: (-.36) - (-.03), $\mathrm{p}<.10)$. Finally, negative affect had a statistically significant direct effect on psychological distress (.78, 95\% percentile confidence interval :(.63)-(.94), $p<.01$ ) and the relationship between positive affect and psychological distress was insignificant (-.03, 95\% percentile confidence interval: (-.23)-(.14), $p>.05)$. The proportion of variance in psychological distress explained by all constructs was $58 \%$ (95\% percentile confidence interval: (.40)-(.79), $p<.001)$. In sum, the direct effect of PA on psychological distress was insignificant, PA did not mediate the relationship between El and Psychological distress, and NA fully mediated the relationship between El and psychological distress (Table 3).

Table 3

Standardized direct and indirect effects

\begin{tabular}{lcccc}
\hline Predictor & Outcomes & & \\
\cline { 2 - 5 } & Positive affect & Negative affect & Psychological distress & \\
\cline { 2 - 5 } El & $\underline{\text { Direct }}$ & $\underline{\text { Direct }}$ & $\underline{\text { Direct }}$ & \multicolumn{1}{l}{ Indirect } \\
& $.56^{* *}$ & $-.34^{* *}$ & .08 & $-.28^{* *}$ \\
Positive & {$[(.42)-(.73)]$} & {$[(-.52)-(-.15)]$} & {$[(-.08)-(.30)]$} & {$[(-.52)-(-.10)]$} \\
affect & - & - & -.03 & - \\
Negative & - & - & {$[(-.23)-(.14)]$} & - \\
affect & & $-78^{* *}$ & - \\
\hline
\end{tabular}

Note: The Confidence Intervals (Cl) are based on the findings from bootstrapping analysis (1000 samples).

${ }^{* *} p<.01$. 


\section{Discussion}

This study investigated the associations between El and variables theoretically linked to it: PA, NA, and psychological distress.

In line with previous studies (e.g., Kafetsios \& Zampetakis, 2008 ; Lopes et al., 2006 ; Sevdalis, Petrides, \& Harvey, 2007) the results demonstrated that El is an important predictor of work affectivity. El was positively related to PA and negatively to NA (Hla \& HIb). Furthermore, the effect of El was stronger for PA as compared to NA, which demonstrates the important role of El in generating positive moods in the work setting. Positive emotions appear to broaden individual's momentary thought-action repertoires (widening the array of the thoughts and actions that come to mind) that promote the building of physical resources (e.g., better health), social resources (e.g., friendship), intellectual resources (e.g., expertise), and psychological resources (e.g., optimism) (broaden-and-build theory: Fredrickson, 2001). Accroding to Tugade and Fredrickson (2001), "emotionally intelligent individuals proactively cultivate positive emotions as paths toward development and growth..... Positive emotions are key resources that should be recognized for their worth..... They appear essential for effective and optimal personal and social functioning". In sum, emotionally intelligent employees are better able to apply these broad and build strategies in work settings (Kafetsios \& Zampetakis, 2008) in order to successfully regulate their negative emotional experiences, which in turn produces beneficial consequences to their psychological and physiological well-being (Tugade \& Fredrickson, 2002).

The results of this study confirmed the assertion that people high on negative affectivity are more vulnerable to poorer psychological well-being outcomes (e.g., anxiety and depression) (Oliver \& Brough, 2002; Spector et al., 2000). This is because, they rate stressors as highly aversive experiences, and ruminate about their negative feelings often, which in turn amplify and increase in number of depressive episodes. The results of this study support key assumptions of Affective Events Theory (AET) (Weiss \& Cropanzano, 1996) which proposes that antecedent events at work with dispositions lead to affective states that in turn, lead to attitudinal and behavioral outcomes. Partial support was found for the mediating role of PA and NA in the relationship between El and psychological distress. Only NA fully mediated the relationship between El and psychological distress. Results suggest that El helps in the formation of affective states at work, which in turn influence employee's psychological health. 
Implications

The results of current study suggest following strategies to manage the issue of psychological distress in work setting. First, special attention should be given to $\mathrm{El}$ during the selection process. Second, intervention strategies should be introduced to enhance El among current employees. Literature provides us evidence that El can be improved via various strategies (Goleman, 1995; Slaski, 2003). Third, based on Fredrickson's (2001) broaden-and-build model of positive emotions, it is suggested that intervention strategies should be introduced within work setting that cultivate positive emotions among employees. According to Fredrickson's (2000, p. 1), positive emotions (such as joy and contentment) broaden an individual's momentary thought-action repertoire, and help in eradicating the hold of negative emotions on an individual's mind and body. Enhancement of positive emotions help in preventing and treating problems such a psychological distress, deeply rooted in negative emotions. Fredrickson's (2000), suggested many intervention strategies that may help in preventing and treating psychological health related problems, as well as, help in building personal strengths, resilience and wellness of people. These intervention strategies include, (a) relaxation therapies (e.g., imagery exercises, muscle exercises, mediation exercises), (b) decreasing the intensity of unpleasant events and increasing the rates of engagement in pleasant activities, (c) cognitive therapies, (d) training employees in finding positive meaning in daily life, (e) building empathy between people and groups. Finally, giving feedback to individuals about their own El levels might give them greater awareness of their own resources, which might help in lowering psychological distress.

\section{Limitations and Recommendations}

The findings of this study are subject to several limitations which are common in this type of research. First, the results are specific to organizations in one geographical area and may or may not be generalizable to other areas. Second, the crosssectional data precludes any inference of causality. The direction of causality (in cross-sectional studies) cannot be established and will have to be examined using longitudinal data. Third, all our respondents were full-time employees and these findings may not be applicable to part-time employees. Four, since all measures were self report based measures; we cannot avoid the social desirability bias. Thus, the utility of self-report El measure may be supplemented by employing performance based measures of El (e.g. MSCEIT). Finally, the relationships among these variables might differ depending on the type of job. Future research can examine these relationships for jobs that differ in terms of intellectual and interpersonal demands (e.g., sales vs. Engineering). 


\section{References}

American Psychological Association (2002). Ethical principles of psychologists and codes of conduct. Washington, DC: APA.

Anderson, J. C., \& Gerbing, D. W. (1988). Structural equation modeling in practice: A review and recommended two-step approach. Psychological Bulletin, 103(3), 41 1-23.

Arbuckle, J. (2006). Amos 7.0 User's Guide. PA: Amos Development Corporation: Spring House.

Ashkanasy, N. M., Härtel, C. E. J., \& Zerbe, W. J. (Eds.). (2000). Emotions in the work place: Theory, research, and practice. Westport, CT: Quorum Books.

Bagozzi, R. P., \& Phillips, L. W. (1982). Representing and testing organizational theories: A holistic construal. Administrative Science Quarterly, 27(3), 459-489.

Bandalos. D. L. (2002). The effects of item parceling on goodness-of-fit and parameter estimate bias in structural equation modeling. Structural Equation Modeling, 9, 78-102.

Barchard, K. A., \& Hakstian, A. R. (2004). The nature and measurement of emotional intelligence abilities: Basic dimensions and their relationships with other cognitive ability and personality variables. Educational and Psychological Measurement, 64 (3), 437-462.

Bar-On, R. (1997). The emotional intelligence Inventory (EQ-i): Technical manual. Toronto: Multi-Health Systems.

Bauld, R., \& Brown, R. F. (2009). Stress, psychological distress, psychosocial factors, menopause symptoms and physical health in women. Maturitas, 62, 160-165.

Bentler, P. M., \& Bonett, D. G. (1980). Significance tests and goodness-of-fit in the analysis of covariance structures. Psychological Bulletin, 88 (3), 588-606.

Besharat, M. A. (2007).Psychometric properties of Farsi version of the Emotional Intelligence Scale-41 (FEIS-41). Personality and Individual Differences, 43, 991-100.

Browne, M. W., \& Cudeck, R. (1993). Alternative ways of assessing model fit. In K. A.

Bollen \& J. S. Long (Eds.), Testing structural equation models (pp. 136-162). Newbury Park, CA: Sage Publications. 
Bruch, M. A., Rivet, K. M., \& Laurenti, H. J. (2000). Type of self-discrepancy and relationships to components of the tripartite model of emotional distress. Personality and Individual Differences 29, 37-44.

Carmeli, A. (2003). The relationship between emotional intelligence and work attitudes, behavior and outcomes: An examination among senior managers. Journal of Managerial Psychology, 18(8), 788-813.

Chan, D. W. (2005). Emotional Intelligence, social coping, and psychological distress among Chinese gifted students in Hong Kong. High Ability Studies, 16(2), 163-178.

Diener, E., Suh, E. M., Lucas, R. E., \& Smith, H. I. (1999). Subjective well-being: Three decades of progress. Psychological Bulletin, 125, 276-302.

Cohen, L., Manion, L., \& Morrison, K. (2000). Research methods in education (5th ed.). NY: RoutledgeFalmer.

Dulewicz, V., Higgs, M., \& Slaski. M. (2003). Measuring emotional intelligence: Content, construct and criterion-related validity. Journal of Managerial Psychology, 18(5), 405-420.

Extremera, N., \& Fernàndez-Berrocal, P. (2006). Emotional intelligence as predictor of mental, social and physical health in university students. The Spanish Journal of Psychology, 9(1), 45-51.

Fernandez-Berrocal, P., Alcaide, R., Extremera, N., \& Pizarro, D. (2006). The role of emotional intelligence in anxiety and depression among adolescents. Individual Differences Research, 4(1), 16-27.

Fisher, C. D. (2000). Mood and emotions while working: Missing pieces of job satisfaction. Journal of Organizational Behavior, 21, 185 - 202.

Fredrickson, B. L. (2000). Cultivating positive emotions to optimize health and well-being. Target article in Prevention and Treatment, 3. Available on the World Wide Web: http://journals.apa.org/prevention.

Fredrickson. B. L. (2001). The role of positive emotions in positive psychology: The broaden-and-build theory of positive emotions. American Psychologist. 56. 218-226.

Gallagher, D. J. (1990). Extraversion, neuroticism, and appraisal of stressful academic events. Personality and Individual Differences, 11, 1053-1057. 
Goldberg, D.P. (1978). Manual of the General Health Questionnaire. NFER-Nelson: Windsor.

Goleman, D. (1995). Emotional Intelligence. New York: Bantam.

Hair, J. F., Anderson, R. E., Tatham, R. L., \& Black, W. C. (2006). Multivariate data analysis. Upper Saddle River, NJ: Prentice-Hall.

Hartel, C. E. J., Zerbe, W. J., \& Ashkanasy, N. M. (Ed.). (2005). Emotions in organizational Behavior. London: Lawrence Erlbaum.

Kafetsios, K. (2007). Work-family conflict and its relationship with job satisfaction and psychological distress: The role of affect at work and gender. Hellenic Journal of Psychology, 4, 15-35.

Kafetsios, K., \& Zampetakis, L. A. (2008). Emotional intelligence and job satisfaction: Testing the mediatory role of positive and negative affect at work. Personality and Individual Differences, 44, 710-720.

Larsen, R.J. (1992).Neuroticism and selective encoding and recall of symptoms: evidence from a combined concurrent-- retrospective study. Journal of Personality and Social Psychology, 62, 480- 88.

Lazarus, R. S. (1993). From psychological stress to the emotions: A history of changing outlooks. In L.W. Porter \& M. Rosenzweig (Eds.), Annual review of psychology (Vol. 44, pp. 1-2). Palo Alto, CA: Annual Reviews.

Little, R. J. A. (1988). A test of missing completely at random for multivariate data with missing values.Journal of the American Statistical Association, 83, 1198-1202.

Lopes, P. N, Grewal, D., Kadis, J., Gall, M., \& Salovey, P. (2006). Evidence that emotional intelligence is related to job performance and affect and attitudes at work. Psicothema, 18, 132-138.

Massé R. (2000). Qualitative and quantitative analyses of psychological distress: methodological complementarity and ontological incommensurability. Qualitative Health Research 10, 411-423. 
Massée, R., Poulin, C., Dassa, C., Lambert, J., Belair, S., \& Battaglini, A. (1998). The structure of mental health higher-order confirmatory factor analyses of psychological distress and well-being measures. Social Indicators Research, 45, 475-504.

Mayer, J. D. \& Salovey, P. (1997). What is emotional intelligence? In P. Salovey \& D. J. Sluyter (Eds.), Emotional development and emotional intelligence: Educational implications (pp. 3-27). New York: Basic Books.

Mayer, J. D., Salovey, P., \& Caruso, D. (2000). Competing models of emotional intelligence. In Handbook of Human Intelligence, (pp. 396-420). New York: Cambridge University Press.

Mayer, J. D., Salovey, P., Caruso, D., \& Sitarenios, G. (2003). Measuring emotional intelligence with the MSCEIT V2.0. Emotion, 3, 97-105.

Miklolajczak, M., Menil, C., \& Luminet, O. (2007). Explaining the protective effort of trait emotional intelligence regarding occupational stress: Exploration of emotional labor processes. Journal of Research in Personality, 41, 1107-1117.

Miles, J., \& Shevlin, M. (2004). Applying regression and correlation: A guide for students and researchers. London: Sage Publications.

Morris, J., \& Feldman, D. (1996). The dimensions, antecedents, and consequences of emotional labor. Academy of Management Review, 21, 986-1010.

Oliver, K., \& Brough, P.(2002).Cognitive appraisal, negative affectivity and psychological well-being. New Zealand Journal of Psychology, 31, 2-7.

Petrides, K. V., \& Furnham, A. (2001). Trait emotional intelligence: Psychometric investigation with reference to established trait taxonomies. European Journal of Personality, 15, 425-448.

Petrides, K. V., Pérez-Gonzalez, J. C., \& Furnham, A. (2007). On the criterion and incremental validity of trait emotional intelligence. Cognition and Emotion, 21 , 26-55.

Petrides, K. V., Pita, R., \& Kokkinaki, F. (2007). The location of trait emotional intelligence in personality factor space. British Journal of Psychology, 98, 273-289.

Ridner, S. H. (2004). Psychological distress: Concept analysis. Journal of Advanced Nursing, 45(5), 536-546. 
Salovey, P., \& Mayer, J. (1990). Emotional Intelligence. Imaginations, Cognition and Personality, 9, 185-211.

Salovey, P., Bedell, B.T., Detweiler, J.B., \& Mayer, J.D. (1999). Coping intelligently: Emotional intelligence and the coping process. In C.R. Snyder (Ed.), Coping: The psychology of what works (pp. 141-164). New York: Oxford Psychology Press.

Salovey, P., Rothman, A.J., Detweiler, J.B., \& Steward, W.T. (2000). Emotional states and physical health. American Psychologist, 55, 110-121.

Schumacker, R. E., \& Lomax, R. G. (1996). A beginner's guide to structural equation modeling. Mahwah, N. J : Lawrence Erlbaum Associates.

Schutte, N. S., Malouff, J. M., Hall, L. E., Haggerty, D. J., Cooper, J. T., Golden, C. J., et al. (1998). Development and validation of a measure of emotional intelligence. Personality and Individual Differences, 25, 167-177.

Sevdalis, N., Petrides, K. V., \& Harvey, N. (2007). Trait emotional intelligence and decisionrelated emotions. Personality and Individual Differences, 42, 1347-1358.

Slaski, M. (2003). Emotional intelligence training and its implications for stress, health, and performance. Stress and Health, 19(4), 233-9.

Slaski, M., \& Cartwright, S. (2003). Emotional intelligence training and its implications for stress, health and performance. Stress and Health, 19, 233-239.

Spector, P. E., Zapf, D., Chen P. Y., \& Frese, M. (2000). Why negative affectivity should not be controlled in job stress research: Don't throw the baby out with the bath water. Journal of organizational Behavior, 21 , 79-95.

StatSoft. (2001). Statistica for Windows v. 6.0. Tulsa, OK: StatSoft. Inc.

Suliman, A. M., \& Al-Shaikh, F. N. (2006). Emotional intelligence at work: Links to conflict and innovation. Employees Relations, 29(2), 208-220.

Taylor, G.J. (2001). Low emotional intelligence and mental illness. In J. Ciarrochi, \& J.P. Forgas (Eds), Emotional intelligence in everyday life: A scientific enquiry (pp. 67-81). Philadelphia, PA: Taylor \& Francis. 
Tsaousis, I., \& Nikolaou, I. (2005). Exploring the relationship of emotional intelligence with physical and psychological health functioning. Stress and Health 21: 77-86.

Tugade, M. M., \& Fredrickson, B. L. (2002). Positive emotions and emotional intelligence. In L. F. Barrett \& P. Salovey (Eds.) The wisdom of feelings: Psychological processes in emotional intelligence (pp. 319 -340). New York. NY: Guilford Press.

Veit, C. T., \& Ware, J. E. (1983). The structure of psychological distress and well-being in general populations. Journal of Consulting and Clinical Psychology, 51, 730-742.

Watson, D., \& Clark, L. A. (1984). Negative affectivity: The disposition to experience aversive negative states. Psychological Bulletin, 96, 465-490.

Watson, D., \& Pennebaker, J. W. (1989). Health complaints, stress and distress: exploring the central role of negative affectivity. Psychological Review. 96, 234-254.

Watson, D., Clark, L.A, \& Tellegen, A. (1988). Development and validation of brief measures of positive and negative affect: The PANAS scales. Journal of Personality and Social Psychology, 54, 1063-1070.

Weiss, H. M., \& Cropanzano, R. (1996). Affective events theory: A theoretical discussion of the structure, causes and consequences of affective experiences at work. In B. M. Staw \& L. L. Cummings (Eds.), Research in organizational behavior (Vol. 19, pp. 1-74). Greenwich, CT: JAI.

Weiss, H. M., Nicholas, J. P., \& Daus, C. S. (1999). An examination of the joint effects of affective experiences and job satisfaction and variations in affective experiences over time. Organizational Behavior and Human Decision Processes, 78, 1-24.

Wilkinson, R., \& Walford, W. (1998). The measurement of adolescent psychological health: one or two dimensions? Journal of Youth and Adolescence, 27(4), 443-445.

Wong, C.-S., \& Law, K. S. (2002). The effects of leader and follower emotional intelligence on performance and attitude: An exploratory study. The Leadership Quarterly, 13, 243274. 
About the author:

Jahanvash KARIM

The author is currently enrolled as a PhD scholar at CERGAM, Institute d'Administration des Entreprises d'Aix-en-Provence, France. In his research he focuses on the relationship between trait emotional intelligence and ability emotional intelligence with particular reference to cultural influences. His work has been published in Euro Asia Journal of Management and The Icfai University Journal of Organizational Behaviour. 